\title{
Ethnicity, Cerebrovascular Diseases and Atherosclerosis-Related Syndromes and Phenomena in Northern Israel \\ Gregory Telman*
}

Department of Neurology, Faculty of Medicine, Rambam Health Care Campus and Technion, Haifa, Israel

\section{Description}

Rambam Health Care Campus is the largest tertiary hospital in the northern Israel, serving population of more than two million, and is the tertiary referral center for other regional hospitals. The population of northern Israel is mainly bi-ethnic with almost equal Jewish and Arab population and minimal mingling between these two ethnic groups.

During last year, we conducted a number of retrospective hospitalbased studies on cerebrovascular patients, mainly acute ischemic stroke and transient ischemic attack (TIA) patients, looking at ethnicity as possible predictor for different atherosclerosis-related syndromes and phenomena, when the variation of routine vascular risk factors was also taken into consideration. The aim of this short communication is to show the importance of ethnicity as well as other demographic parameters, vascular diseases and routine vascular risk factors in variety of cerebrovascular diseases and atherosclerosis-related syndromes and phenomena in bi-ethnic population of northern Israel. Assignment of ethnicity in all studies was done by first and last name along with a place of residence and place of birth. This method of ethnic background determination was previously examined with almost perfect correlation between the four independent observers, $K=0.96$, according to Fleiss' Kappa [1].

The profile of vascular diseases and vascular risk factors in Arab and Jewish patients with acute ischemic stroke and acute intracerebral hemorrhage (ICH) is presented in Table 1. Diabetes mellitus was the only vascular risk factors occurring significantly more often in the stroke and ICH patients of Arab origin. The examined atherosclerosisrelated syndromes and phenomena included carotid plaques presence, carotid intima-media thickness, distribution of aortic atheromas, intracranial stenosis and cerebrovascular resistance as evaluated by pulsatility index (PI).

The factor of ethnicity was significant only in patients with acute ischemic stroke and aortic atheromas, when patients of Jewish origin were significantly more prone to develop aortic atheromas. For other atherosclerosis-related syndromes and markers, biologic parameters

\begin{tabular}{|c|c|c|c|c|c|c|}
\hline \multirow[b]{2}{*}{ Risk Factor } & \multicolumn{2}{|c|}{$\begin{array}{c}\text { Acute Intracerebral } \\
\text { Hemorrhage }\end{array}$} & \multirow[b]{2}{*}{$P$} & \multicolumn{2}{|c|}{ Acute Ischemic Stroke } & \multirow[b]{2}{*}{$P$} \\
\hline & $\begin{array}{l}\text { Jewish } \\
\text { patients } \\
(\mathrm{N}=417)\end{array}$ & $\begin{array}{c}\text { Arab } \\
\text { patients } \\
(\mathrm{N}=129)\end{array}$ & & $\begin{array}{l}\text { Jewish } \\
\text { patients } \\
(\mathrm{N}=499)\end{array}$ & $\begin{array}{c}\text { Arab } \\
\text { patients } \\
(\mathrm{N}=228)\end{array}$ & \\
\hline Hypertension & $302(72.6 \%)$ & $91(70.5 \%)$ & NS & $294(58.9 \%)$ & $\begin{array}{c}136 \\
(59.7 \%)\end{array}$ & NS \\
\hline Diabetes & $86(20.6 \%)$ & $48(37.2 \%)$ & 0.0002 & $149(29.9 \%)$ & $\begin{array}{c}110 \\
(48.3 \%)\end{array}$ & $\varangle 0.0001$ \\
\hline Hyperlipidemia & $132(31.7 \%)$ & $36(27.9 \%)$ & NS & $192(38.5 \%)$ & $\begin{array}{c}76 \\
(33.3 \%)\end{array}$ & NS \\
\hline Smoking & $48(11.5 \%)$ & $25(19.5 \%)$ & 0.025 & $148(30 \%)$ & $\begin{array}{c}64 \\
(28.1 \%)\end{array}$ & NS \\
\hline $\begin{array}{l}\text { Ischemic heart } \\
\text { disease }\end{array}$ & $106(25.5 \%)$ & $24(18.8 \%)$ & NS & $91(18.2 \%)$ & $54(23.7 \%)$ & 0.01 \\
\hline $\begin{array}{c}\text { Atrial } \\
\text { fibrillation }\end{array}$ & $76(18.3 \%)$ & $16(12.4 \%)$ & NS & $34(6.8 \%)$ & $16(7 \%)$ & NS \\
\hline
\end{tabular}

Table 1: Comparison of risk factors profile in Arab and Jewish patents with $\mathrm{ICH}$ or ischemic stroke. and routine vascular risk factors, but not ethnicity, were found to be significant predictors in acute ischemic stroke and TIA patients in northern Israel (Table 2).

\section{Discussion}

Ethnic/race differences are well established in many nosologies and many populations [2-5]. Stroke and other cerebrovascular diseases are influenced by ethnicity in many aspects. Extensive literature data may be found about the relation between race/ethnicity and distribution of vascular risk factors [6-8] as well as between race/ethnicity and many clinical variables, such as disease prevalence, clinical course, complications, outcome and mortality [9-12]. The bi-ethnic character of the northern Israel population gives an opportunity to study the possible influence of ethnicity on different nosologies. This was never done before about cerebrovascular patients. We found considerable similarity in distribution of routine vascular risk factors in acute ischemic stroke and ICH patients of Jewish and Arab origin [13,14], when the only significant difference was a higher prevalence of diabetes in patients of Arab origin. The higher prevalence of diabetes in minorities stroke patients was found in another Israeli study [15] as well as in other populations [16-18]. This phenomenon is explained by both genetic and cultural mechanisms.

On the other hand, an influence of ethnicity on examining atherosclerosis-related phenomena and syndromes in our population was limited [19]. From five examined syndromes, four-intracranial stenosis [20], presence of carotid plaques [21], carotid intima-media thickness and cerebrovascular resistance (submitted data)-were influenced only by biological factors (age and gender) or vascular risk factors. The retrospective nature of the studies included in this report should be mentioned as a limitation, which is partially overwhelmed by a large sample size and carefully performed studies protocols.

In conclusion, in stroke and TIA patients of northern Israel many atherosclerosis-related phenomena and syndromes are influenced mainly by biological and routine vascular risk factors, when the influence of ethnicity is limited. Further studies should concentrate on differences between these two groups in income, management of hypertension and diabetes, marital state, administrative support, medical counseling, nutrition, physical activity and many other factors in attempt to explain peculiarities of cerebrovascular diseases and

*Corresponding author: Gregory Telman, Department of Neurology, Rambam Health Care Campus and Technion Faculty of Medicine, Haifa, Israel, Tel: +972 4 8542161; E-mail: g_telman@rambam.health.gov.il

Received January 19, 2016; Accepted February 16, 2016; Published February 19, 2016

Citation: Telman G (2016) Ethnicity, Cerebrovascular Diseases and AtherosclerosisRelated Syndromes and Phenomena in Northern Israel. Brain Disord Ther 5: 208. doi:10.4172/2168-975X.1000208

Copyright: $(2016$ Telman G. This is an open-access article distributed under the terms of the Creative Commons Attribution License, which permits unrestricted use, distribution, and reproduction in any medium, provided the original author and source are credited. 
Citation: Telman G (2016) Ethnicity, Cerebrovascular Diseases and Atherosclerosis-Related Syndromes and Phenomena in Northern Israel. Brain Disord Ther 5: 208. doi:10.4172/2168-975X.1000208

Page 2 of 2

\begin{tabular}{|c|c|c|c|c|c|}
\hline $\begin{array}{l}\text { Syndrome } \\
\text { Risk factor }\end{array}$ & $\begin{array}{c}\text { Intracranial } \\
\text { stenosis } \\
\text { (Acute ischemic stroke } \\
\text { and TIA N=1344), } P\end{array}$ & $\begin{array}{c}\text { Aortic } \\
\text { atheromas } \\
\text { (Acute ischemic stroke, } \\
\mathrm{N}=509), \mathrm{P}\end{array}$ & $\begin{array}{c}\text { Carotid } \\
\text { disease } \\
\text { (Acute ischemic stroke } \\
\mathrm{N}=1378 \text { ), } \mathrm{P}\end{array}$ & $\begin{array}{c}\text { Intima-Media } \\
\text { Thickness } \\
\text { (Acute ischemic stroke } \\
\text { and TIA, N=777), } P\end{array}$ & $\begin{array}{c}\text { Cerebro-vascular } \\
\text { resistence by } \mathrm{PI}^{*} \text { (Acute } \\
\text { ischemic stroke } \\
\text { and TIA, N=862), } \mathrm{P}\end{array}$ \\
\hline $\begin{array}{c}\text { Ethnicity } \\
\text { Arab vs. Jewish) }\end{array}$ & NS & 0.02 & NS & NS & NS \\
\hline Age (per year) & NS & 0.0002 & $<0.0001$ & $<.0001$ & $<.0001$ \\
\hline $\begin{array}{c}\text { Gender } \\
\text { (male vs. female) }\end{array}$ & NS & NS & 0.002 & 0.0005 & NS \\
\hline Hypertension & NS & NS & NS & $<.0001$ & NS \\
\hline Diabetes & 0.0016 & NS & 0.049 & $<.0001$ & $<.0001$ \\
\hline Smoking & NS & 0.0003 & 0.04 & NS & NS \\
\hline Hyperlipidemia & NS & NS & 0.049 & NS & NS \\
\hline $\begin{array}{l}\text { Ischemic Heart } \\
\text { Disease }\end{array}$ & NS & NS & NS & NS & NS \\
\hline $\begin{array}{c}\text { Peripheral } \\
\text { Vascular Disease }\end{array}$ & 0.0097 & NS & NS & 0.0065 & NS \\
\hline
\end{tabular}

Table 2: Logistic regression analysis of possible predictors of atherosclerosis-related syndromes and phenomena in acute ischemic stroke and TIA patients in bi-ethnic population of northern Israel.

atherosclerosis-related phenomena in bi-ethnic population of northern Israel.

\section{References}

1. Telman G, Kouperberg E, Herskovitz M, Hurani H, Sprecher E (2011) Assignment of ethnicity in patients with acute ischemic stroke in northern Israel. Health 3: 444-446.

2. Tawk R, Abner A, Ashford A, Brown CP4 (2015) Differences in Colorectal Cancer Outcomes by Race and Insurance. Int J Environ Res Public Health 13.

3. Rodriguez F, Joynt KE, López L, Saldaña F, Jha AK (2011) Readmission rates for Hispanic Medicare beneficiaries with heart failure and acute myocardial infarction. Am Heart J 162: 254-261.

4. Leong AB, Ramsey CD, Celedón JC (2012) The challenge of asthma in minority populations. Clin Rev Allergy Immunol 43: 156-183.

5. Crews DC, Pfaff T, Powe NR (2013) Socioeconomic factors and racial disparities in kidney disease outcomes. Semin Nephrol 33: 468-475.

6. Gentile NT, Seftchick MW (2008) Poor outcomes in Hispanic and African American patients after acute ischemic stroke: influence of diabetes and hyperglycemia. Ethn Dis 18: 330-335.

7. Zweifler RM, McClure LA, Howard VJ, Cushman M, Hovater MK, et al. (2011) Racial and geographic differences in prevalence, awareness, treatment and control of dyslipidemia: the reasons for geographic and racial differences in stroke (REGARDS) study. Neuroepidemiology 37: 39-44

8. Judd SE, Gutiérrez OM, Newby PK, Howard G, Howard VJ, et al. (2013) Dietary patterns are associated with incident stroke and contribute to excess risk of stroke in black Americans. Stroke 44: 3305-3311.

9. Bhandari VK, Kushel M, Price L, Schillinger D (2005) Racial disparities in outcomes of inpatient stroke rehabilitation. Arch Phys Med Rehabil 86: 20812086.

10. Karve SJ, Balkrishnan R, Mohammad YM, Levine DA (2011) Racial/ethnic disparities in emergency department waiting time for stroke patients in the United States. J Stroke Cerebrovasc Dis 20: 30-40.
11. Pathak EB, Sloan MA (2009) Recent racial/ethnic disparities in stroke hospitalizations and outcomes for young adults in Florida, 2001-2006. Neuroepidemiology 32: 302-311.

12. Hanchate AD, Schwamm LH, Huang W, Hylek EM (2013) Comparison of ischemic stroke outcomes and patient and hospital characteristics by race/ ethnicity and socioeconomic status. Stroke 44: 469-476.

13. Telman G, Kouperberg E, Sprecher E, Yarnitsky D (2010) Ethnic differences in ischemic stroke of working age in northern Israel. J Stroke Cerebrovasc Dis 19: $376-381$.

14. Telman G, Hlebtovsky A, Sprecher E, Zaaroor M, Kouperberg E (2010) Ethnic disparities in first primary intracerebral hemorrhage in northern Israel. Neuroepidemiology 34: 208-213.

15. Greenberg E, Treger I, Schwarz J (2011) Age, gender and risk factor disparities in first-stroke Jewish and Arab patients in Israel undergoing rehabilitation. Isr Med Assoc J 13: 680-683.

16. Feigin V, Carter K, Hackett M, Barber PA, McNaughton H, et al. (2006) Ethnic disparities in incidence of stroke subtypes: Auckland Regional Community Stroke Study, 2002-2003. Lancet Neurol 5: 130-139.

17. Bravata DM, Wells CK, Gulanski B, Kernan WN, Brass LM, et al. (2005) Racia disparities in stroke risk factors: the impact of socioeconomic status. Stroke 36: 1507-1511.

18. Cushman M, Cantrell RA, McClure LA, Howard G, Prineas RJ, et al. (2008) Estimated 10-year stroke risk by region and race in the United States: geographic and racial differences in stroke risk. Ann Neurol 64: 507-513.

19. Telman G, Kouperberg E, Sprecher E, Agmon Y (2012) Aortic atheromas in acute ischemic stroke patients in northern Israel. J Atheroscler Thromb 19: 169 175

20. Telman G, Hurani H, Sprecher E, Kouperberg E (2015) Middle cerebral artery stenosis in patients with acute ischemic stroke and TIA in Israel. AJNR Am J Neuroradiol 36: 46-49.

21. Telman G, Sprecher E, Kouperberg E (2012) Carotid disease in acute ischemic stroke patients of northern Israel. Acta Neurol Scand 126: 398-403. 